\title{
COLABORAÇão FAMÍLIA-ESCOLA EM UM PROCEDIMENTO DE LEITURA PARA ALUNOS DE SÉRIES INICIAIS
}

\author{
Eulália H. Maimoni ${ }^{1}$
}

Márcia E. Bortone ${ }^{2}$

\begin{abstract}
Resumo
O presente estudo teve por objetivo utilizar o procedimento de "leitura conjunta", envolvendo a colaboração dos pais. Estes deveriam ouvir a leitura de textos, duas vezes por semana, feita pelo filho, aluno de segunda série do ensino fundamental, que escolhia um tema do seu interesse. Cada sessão durava cinco minutos, havendo um teste de compreensão da leitura, aplicado antes e depois das seis semanas de uso do procedimento. Os pais responderam a um questionário sobre a sua percepção acerca da leitura do filho. Houve melhora no desempenho em leitura e, embora o grupo de controle também tenha melhorado, os dados mostraram a possibilidade da participação dos pais no processo de construção da leitura do filho.

Palavras-chave: envolvimento de pais na vida escolar do aluno; relação família-escola; proficiência em leitura; percepção de pais sobre leitura.
\end{abstract}

\section{Family-sch0ol Collaboration in a Reading Procedure for Inicial Grades}

\begin{abstract}
The present study had for objective to use the procedure of "paired reading", involving the parents' collaboration. The parents (mother or father) should hear the reading of texts, twice a week, done by the son, student of second grade of the fundamental teaching, that chose a theme of its interest. Each session lasted five minutes, having a test of understanding of the reading, applied before and after the six weeks of use of the procedure. The parents answered to a questionnaire, about its perception concerning the son's reading. There was improvement in the acting in reading and, although the control group has also improved, the data showed the possibility of the parents' participation in the process of construction of the son's reading.

Key-words: educational involvement of parents; relation family-school; proficiency in reading; parents' perception on reading.
\end{abstract}

\section{INTRODUÇÃ̃o}

\begin{abstract}
A colaboração família-escola tem sido bastante enfatizada, como uma das metas para a educação no milênio que se inicia, como pode ser observado no relatório elaborado para a UNESCO (Delors, 2000). Estudos recentes têm sido desenvolvidos nessa direção, mostrando as vantagens dessa parceria para a escola e para os alunos (DiNucci, 1997; Bhering \& SirajBlatchford, 1999; McBride, 1999). Porém, antes da entrada da criança para a escola, a família se coloca como a principal mediadora das aprendizagens infantis e uma das variáveis, que têm sido estudadas diz respeito a como se dá essa mediação e no que ela pode
\end{abstract}

ampliar o potencial de aprendizagem dos alunos, facilitando o trabalho futuro de professores (Klein, 1992).

A experiência da aprendizagem mediada consiste em uma situação de interação entre um adulto ou colega mais capaz e um aprendiz. Baseando-se em conclusões de pesquisadores a respeito, Linhares (1995:24) diz:

Na experiência de aprendizagem mediada, os eventos são selecionados, ordenados, filtrados e dotados de significado específico por agentes mediadores (pais, professores ou qualquer pessoa mais habilita-

\footnotetext{
${ }^{1}$ Doutora em Psicologia Escolar pela USP-SP e docente da Universidade de Uberaba. Endereço: Av. Dr. Misael Rodrigues de Castro, 569. Cep 38408-184 - Uberlândia - MG. Fone: (34) 3219-9841. E-mail: eulalia@triang.com.br

${ }^{2}$ Doutora em Lingüística pela UFRJ e docente do Centro Universitário do Triângulo (UNIT).

Agradecemos a participação do aluno de Iniciação Científica, Thiago O. Paiva, pela participação na pesquisa.
} 
da), a fim de modificar o repertório das crianças e estimular a manifestação de níveis mais complexos de funcionamento, revelando o seu potencial para mudança ou para a aprendizagem.

Em seu estudo, a referida autora mostra como ocorre a mediação em uma situação de estimulação cognitiva de crianças com dificuldade de aprendizagem.

$\mathrm{O}$ interesse do presente estudo refere-se mais a atividades de leitura, em que pais podem aprender a exercer a mediação de aprendizagens importantes, para que seu filho se torne um leitor proficiente.

\section{O ENVOLVIMENTO DE PAIS NA VIDA ESCOLAR}

\section{DO ALUNO}

O envolvimento de pais na vida escolar do filho foi bastante pesquisado na década de noventa, tentando mostrar o quanto pode ser produtiva a parceria escola-família. Esses estudos tentaram, de início, definir o que é esse envolvimento de pais. Alguns pesquisadores o definiram como o grau em que pais participam das atividades associadas à vida escolar do filho, tais como: acompanhar tarefas e trabalhos escolares, ver caderno com as lições da escola, verificar se o filho fez as tarefas, estabelecer horário de estudo, informar-se sobre matérias e provas, entre outras (Freitas, Maimoni \& Siqueira, 1994 e de Maimoni \& Miranda, 1999). Outros pesquisadores o definiram como as interações do filho direcionadas ao seu próprio desenvolvimento, encorajamento deste desenvolvimento, através do reforço aos esforços da criança e arranjo de experiências de enriquecimento cultural (Bradley, Caldwell \& Rock, 1998); outros consideram que um pai envolvido seja aquele que auxilia nas tarefas de casa, quando é solicitado, participa da programação da escola, assiste às atividades esportivas e extracurriculares do filho, auxilia o filho adolescente a selecionar cursos e toma conhecimento de como o filho está indo na escola (Steinberg, Dornbush e Darling, 1992). Há ainda alguns estudos que propuseram um modelo tridimensional, esclarecendo que o envolvimento dos pais pode ser demonstrado pelo seu comportamento em relação à escola, pela sua disponibilidade afetiva e pessoal, relacionada à vida escolar do filho e pela oportunidade de experiência intelectual/cognitiva, que estes pais proporcionam aos seus filhos (Grolnick \& Slowiaczeck, 1994).
A pesquisa de Grolnick e Slowiaczeck (1994) descobriu que, se professores percebem que os pais são envolvidos, atendem melhor ao aluno na escola; se o filho percebe pais como envolvidos, podem ser influenciados pelo comportamento dos pais, no que se refere à importância que dão à escola. Por outro lado, filhos que tiram boas notas podem levar mães a serem mais envolvidas e mãe envolvida influencia o envolvimento do pai.

Já a pesquisa brasileira de Freitas, Maimoni e Siqueira (1994) revelou um dado inesperado, pois, das nove variáveis analisadas nesse estudo, como possíveis determinantes do envolvimento de pais na vida escolar do aluno, apenas duas mostraram forte relação com envolvimento: série cursada pelo filho e horário de trabalho do pai, quando se esperava que fosse o horário de trabalho da mãe a mostrar tal resultado. Isso indica que o grau de envolvimento dos pais com os estudos dos filhos parece ser influenciado por duas grandes dimensões: o nível de necessidade do filho e a disponibilidade do pai, e não da mãe. Como a esta vem cabendo, na medida do possível, o acompanhamento escolar do filho, talvez seja preciso reavaliar o papel do pai, quando presente na família, em relação ao aspecto educacional da criança e do jovem.

Um outro dado importante, que surgiu, tanto das pesquisas nacionais, como das estrangeiras, diz respeito à relação entre nível sócio-econômico cultural e envolvimento, mostrando que pais podem se tornar envolvidos com a vida escolar dos seus filhos, independente de seu nível socioeconômico.

A principal preocupação de pesquisadores na área da Educação talvez seja responder à pergunta: por que existem bons e maus alunos? As pesquisas sempre estão tentando chegar a uma resposta por diversos caminhos. O caminho ora escolhido é o de pesquisar sobre a família, já que há muitos indícios de que algumas causas das dificuldades escolares estejam situadas na família, mas que também o auxílio dos pais ao aluno em casa pode ser um importante determinante do sucesso escolar. É o que as pesquisas vêm mostrando, muito embora se reconheça que a família não seja a única responsável nesse particular.

Autores de diferentes orientações teóricas parecem concordar com que nenhum efeito adverso seja irreversível, quando se fala em aprendizagem e em escola. Portanto, um aluno com dificuldades escolares pode ter esse quadro revertido, em qualquer época de sua vida escolar. Bettelheim e Zelan (1992), em 
um quadro de referência psicanalítico, insistem no fato de que uma criança que entre para a escola com uma baixa auto-estima, pode ter essa auto-estima reconstruída, em um ambiente escolar que fortaleça o seu ego, através de experiências de sucesso.

Essa capacidade de reverter efeitos adversos tem sido descrita na literatura a respeito, como resiliência. Marturano (1997: 132) refere-se à resiliência como "capacidade de resistência ao stress em crianças que crescem em condições desfavoráveis, desenvolvendose como adultos que funcionam em um alto nível de bem estar". A mesma autora, com base em outros estudos, faz referência a variáveis que operam como fatores protetivos, aumentando a resiliência. A primeira delas refere-se a características de personalidade (autonomia, auto-estima, orientação social positiva), a segunda, à coesão e ao afeto familiar, sem discórdia e a terceira, à supervisão comportamental ou firmeza e democracia nas relações com o filho.

Um dado que deve ser lembrado aqui é o resultante da pesquisa longitudinal, realizada por Bradley, Caldwell e Rock (1988), que acompanharam 42 alunos, durante dez anos, com avaliações aos dois e dez anos de idade. Os autores encontraram uma relação entre a estabilidade do envolvimento de pais e a competência escolar dos alunos.

Muitos estudiosos, preocupados com essa problemática, e no intuito de restituir aos pais a sua capacidade de criar filhos em condição de serem bem-sucedidos em sua vida escolar futura, projetaram formas e tornálos mais envolvidos desde muito cedo, com as aprendizagens importantes para o desenvolvimento da criança. Uma dessas formas foi idealizada por Feuerstein (1980) e recebeu o nome de Programa de Enriquecimento Instrumental (PEI), que visa a uma ampliação do potencial de aprendizagem de crianças, jovens e adultos, mesmo daqueles mais comprometidos cognitivamente. O mesmo objetivo tem o programa MISC (Mediational Intervention Sensitizing) de Pnina Klein (1992), que se preocupa com a preparação de mães ou outras pessoas que cuidem de crianças, para serem boas mediadoras de aprendizagens importantes para o desenvolvimento das mesmas.

A proposta, que servirá de base para a presente pesquisa, é a de Keith Topping (1989). Esse autor, nas suas primeiras pesquisas em escola, tinha como principal preocupação, obter uma maior participação da família no processo de aprendizagem do aluno. Considerando que existem resistências por parte do pes- soal da escola, que teme a interferência dos pais, por um lado, e que os pais não sabem muito bem como e no que colaborar, Topping $(1990,1994)$ elaborou alguns procedimentos, entre os quais o que denominou "leitura conjunta", em que ações bem definidas são passadas aos pais, a fim de que escola e família saibam claramente o que fazer. Assim, a escola não se sente ameaçada pela interferência dos pais e estes podem realizar suas aspirações de acompanhar mais de perto seus filhos na escola, colaborando efetivamente para que melhorem no seu desempenho em leitura. Além disso, o tempo gasto pelos pais é mínimo, facilitando a tarefa que lhes é proposta, qual seja a de ouvir o filho ler para o pai ou para a mãe, por pelo menos cinco minutos diariamente. A partir dos dados de seus estudos, o pesquisador recomenda que isso seja feito prioritariamente pelo pai, ao invés de pela mãe, se este estiver presente na família.

Um último aspecto e que é tratado por Santos e Joly (1996) refere-se aos benefícios para os próprios pais, que, participando de atividades de leitura conjunta com o filho, podem melhorar a sua leiturização. Assim, acredita-se ser possível que pais possam ser mediados em suas atividades de leitura, tornando-se mais proficientes na mesma e utilizando depois os recursos aprendidos, na mediação das aprendizagens dos filhos em casa, conforme pesquisas anteriores de Bortone, Maimoni e Paiva (2000).

Espera-se, portanto, que um estudo baseado em propostas como essas possa oferecer suporte para um trabalho mais integrado entre família e escola.

\section{A APRENDIZAGEM DA LEITURA}

Uma das grandes preocupações atuais de pais e professores é a de tornar a criança e o adolescente um leitor maduro. Por outro lado, são inúmeras as dificuldades em levar essa criança ou esse jovem a se interessar pela leitura. Esta pesquisa teve, como uma de suas metas, melhorar a leitura do aluno, estimulando o relacionamento desse aluno com a leitura do texto.

Partiu-se do pressuposto de que, para que haja prazer em se ler um texto, é necessário que a criança entenda o que está escrito, e não somente decodifique o texto; que a criança sinta que o texto traz informações novas, as quais irá compartilhar com seu novo ouvinte (o pai). É necessário que a criança perceba que o texto sempre tem algo diferente a ensinar ou, simples- 
mente informar; e, ainda, que o texto tem uma função social, que é a de levar às pessoas informações, conhecimentos, diversão e fruição.

Ao instituir um ouvinte para a leitura, está-se oportunizando uma facilitação dos aspectos acima referidos.

Nesta experiência, o pai age como um mediador, reformulando ou monitorando o processo de compreensão da criança. Esta não lerá o texto de qualquer maneira, pois terá de entendê-lo para que seu ouvinte também entenda. Nesse processo, ela ativará os recursos de entonação e pontuação, o que, por sua vez, auxiliam na compreensão do texto. Como a criança faz previamente a escolha do texto a ser lido e, nessa escolha, ela considera as preferências do seu pai, espera-se que a criança escolha aquilo que para ela faça sentido, ou seja, aquilo que lhe é compreensível. Assim, a tarefa de leitura, que era solitária e nem sempre pressupunha compreensão, passa, dessa forma, a ter caráter de uma "contação de história", o que faz dela uma partilha.

Portanto, o fato de se dar um objetivo para a leitura, parece reforçar o estímulo para a leitura e a compreensão dos textos lidos. Aliado a isso, a escolha dos textos por parte das crianças, a receptividade e a participação do pai podem se constituir em fortes elementos para quebrar com a sistemática escolar de leitura obrigatória, aparentemente sem sentido e, muitas vezes, só de decodificação, para se chegar a uma leitura compartilhada, significativa e prazerosa.

Segundo Kleiman (1997: 30), "há evidências inequívocas de que nossa capacidade de processamento e de memória melhoram significativamente, quando é fornecido um objetivo para uma tarefa". Em uma experiência com seus alunos, a lingüista solicitou à turma para fazer um resumo de um texto lido em sala de aula, e escolheu alguns alunos aleatoriamente, cujos resumos seriam publicados no jornal da escola. Esses alunos, que tinham um objetivo específico, não só escreveram os melhores resumos, como também demonstraram terem percebido melhor o tema do texto original.

Um outro aspecto que foi considerado neste estudo, ao se proceder à aplicação dos textos para a avaliação da leitura, é a existência dos três níveis de leitura, ressaltados por Dell'Isola, em seu livro 'Leitura: Inferências e Contexto Sócio-Cultural' (1991).

Em primeiro lugar, a leitura objetiva, na qual se aborda o que está explícito no texto, fazendo-se le- vantamento léxico contextualizado. Em segundo lugar, a leitura inferencial, na qual o aluno é levado detectar as inferências, isto é, o que está implícito no texto. Este nível de leitura é essencial, pois aqui o aluno faz as suas inferências baseando-se na sua visão de mundo, suas experiências e sua ideologia; enfim, em seu contexto sociocultural. É o momento da interação leitor/texto. O leitor, durante a leitura, age sobre o texto e constrói significados de acordo com as suas perspectivas e sua visão de mundo. Sendo assim, é lógico que o sentido de um texto não será o mesmo para todos os alunos. Também Dell'Isola (1991: 31) esclarece que "leitura é um processo onde o leitor participa não decodificando sinais, mas sobretudo dando sentido aos sinais". O terceiro nível de leitura é a leitura avaliativa, na qual o aluno extrapola o texto, manifestando sua postura crítica, baseando-se nas suas ideologias, seus julgamentos pessoais e suas reações diante das idéias expressas pelo autor. A leitura avaliativa é considerada a "ponte" para produção do texto. Assim, se o professor conseguir passar da leitura objetiva para a avaliativa estará dando "voz" ao aluno e permitindo que ele seja sujeito do seu discurso.

Com base nessas considerações sobre leitura e o envolvimento de pais em atividades de leitura do filho, foram definidos os objetivos deste estudo: primeiro, verificar se a participação de pais, através do procedimento de leitura conjunta, pode melhorar o desempenho de alunos em compreensão de leitura e, segundo, conhecer as percepções desses pais, a respeito da leitura do filho e das formas de mediação dessa aprendizagem.

\section{MÉTODO}

\section{Sujeitos}

Participaram deste estudo 28 alunos de segunda série do ensino fundamental, de uma escola mantida pela Universidade de Uberaba, sendo 18 do sexo feminino e 10 do sexo masculino. Participaram também a bibliotecária, as duas professoras, já que os alunos pertenciam a duas salas de aula, e os pais desses alunos.

A classe do período vespertino foi destinada, aleatoriamente, a passar pelo procedimento de leitura conjunta, sendo, portanto, o grupo experimental, composto de 12 (doze) meninas e 3 (três) meninos. A outra classe 
de segunda série da escola, do período matutino, foi o grupo de controle, composto de 6 (seis) meninas e 7 (sete) meninos.

Todas as famílias dos alunos eram de baixa renda, de acordo com a triagem socioeconômica feita pela escola, para o ingresso na mesma. Apenas em duas famílias o pai estava ausente.

\section{Procedimento}

a) Procedimento de coleta de dados:

Inicialmente, foi feita a avaliação da proficiência em leitura e escrita, através de um texto aplicado a todos os alunos das duas classes, durante o horário de aula, pelas professoras, com a presença do bolsista. Cada uma leu o texto impresso para seus alunos da forma habitual, sendo que depois eles responderam às questões propostas para a verificação da compreensão do mesmo.

Foi organizada também uma reunião de pais pela direção da escola, para que fossem informados dos objetivos do estudo e dessem sua aquiescência. Nessa reunião, foram apresentados os pesquisadores e foi exposto, através de um fluxograma, conforme Anexo I, o procedimento de leitura conjunta, adaptado de Topping (1989). Foi feita também uma simulação de como proceder, com a participação de um aluno e do bolsista no papel de pai.

Após serem resolvidas as dúvidas, os pais presentes assinaram uma lista, concordando em participar do estudo. A sua participação consistia em ler junto com o filho e depois ouvi-lo ler, por cerca de cinco minutos, um texto escolhido pela criança na escola, duas vezes por semana, durante 6 semanas.

Os alunos levavam textos para casa a cada semana, cuja escolha era feita entre textos previamente selecionados (montou-se uma pasta com textos de jornais e revistas) em dias marcados, na biblioteca da escola, junto com a bibliotecária ou o bolsista que aproveitava o momento para uma conversa com as crianças, a fim de verificar como o procedimento estava sendo seguido em casa. Verificou-se, nessas oportunidades, que os alunos estavam muito motivados para ler e que não apenas um dos pais ou responsável ouvia a sua leitura, pois o texto era lido várias vezes para outras pessoas da casa.

Após as seis semanas, os alunos foram reavaliados, por meio de outro texto equivalente ao primeiro, com questões para verificação da proficiência em leitura e escrita. A percepção dos pais sobre a leitura dos filhos, com a utilização desse programa de leitura conjunta, foi avaliada por meio de um questionário enviado aos mesmos pelas professoras.

b) Procedimento de avaliação da compreensão em leitura:

A compreensão em leitura foi avaliada, mediante dois critérios, um quantitativo e outro qualitativo. $\mathrm{O}$ procedimento quantitativo considerou o número de respostas corretas, em relação ao texto dado. O procedimento qualitativo considerou o tipo de resposta dada, recebendo pesos diferentes as questões que exigiam respostas inferenciais $(1,0)$ ou literais $(0,5)$, ou que eram avaliativas $(1,0)$ ou verificavam a sequiência temporal dos acontecimentos relatados nos textos $(1,0)$.

A interpretação dos textos aplicados aos alunos no início da pesquisa e após o procedimento de leitura conjunta, seguiu a proposta de Dell'Isola (1991) de leitura em três níveis de compreensão:

Nivel informativo ou objetivo - é acessado pelas informações superficiais do texto e aborda o que está explícito, tais como personagens, local, tema.

Nível de pressuposição ou inferencial - nesse nível, o aluno é levado a detectar as inferências, isto é, o que está implícito no texto, a partir da construção de significados, de acordo com suas perspectivas e sua visão de mundo. É o momento da interação autor-leitor. A percepção das inferências é essencial para que haja uma leitura significativa, pois muito da coerência interna de um texto está implícita e só é ativada por meio das estratégias inferenciais.

Nivel crítico ou avaliativo - nesse nível, o aluno extrapola o texto, manifestando seu ponto de vista e suas reações diante das idéias expressas pelo autor . O nível avaliativo é considerado a "fonte" para a futura produção de texto do educando, pois permite que ele aprenda a fazer uma avaliação crítica e se posicionar a respeito do que lê.

A elaboração das questões de interpretação dos textos aplicados aos alunos deste estudo, antes e após o procedimento de leitura conjunta, e que serviram de parâmetros para a avaliação do desempenho dos mesmos, seguiram, portanto, a proposta de leitura nos três níveis: objetiva, inferencial e avaliativa. 


\section{Resultados}

Os dados quantitativos e qualitativos, bem como as porcentagens de respostas dadas pelos pais ao questionário, encontram-se nas Tabelas 1, 2 e 3. Os dados das duas primeiras tabelas passaram por tratamento estatístico, para ser verificada a significância das diferenças apresentadas entre o grupo experimental e o de controle, bem como para se poder concluir sobre os efeitos do procedimento utilizado.

Com interesse em verificar a existência ou não de diferenças significantes entre os resultados encontra-

Tabela 1. Freqüência de acertos em compreensão de leitura, antes e após o procedimento de leitura conjunta, do grupo de controle.

\begin{tabular}{c|c|c|c|c}
\hline & \multicolumn{2}{|c|}{ Análise qualitativa } & \multicolumn{2}{c}{ Análise quantitativa } \\
\hline Sexo & Antes & Após & Antes & Após \\
\hline F & 8.0 & 10.0 & 7.0 & 8.0 \\
M & 7.0 & 9.0 & 7.0 & 7.0 \\
F & 6.5 & 9.0 & 6.0 & 7.0 \\
M & 1.5 & 9.0 & 1.0 & 7.5 \\
F & 4.0 & 6.5 & 3.0 & 5.5 \\
F & 7.0 & 10.0 & 6.0 & 8.0 \\
M & 1.0 & 6.5 & 1.0 & 5.0 \\
F & 6.5 & 8.5 & 5.0 & 6.0 \\
M & 9.0 & 8.0 & 8.0 & 6.5 \\
F & 1.5 & 6.5 & 1.0 & 8.0 \\
M & 6.5 & 10.0 & 5.0 & 7.0 \\
M & 2.0 & 8.5 & 2.0 & 5.0 \\
M & 6.0 & 7.5 & 6.0 & 87.0 \\
\hline TOTAL & 66.5 & 109.0 & 58.0 & \\
\hline
\end{tabular}

Tabela 2. Freqüência de acertos antes e após o procedimento de leitura conjunta, do grupo experimental.

Análise qualitativa

Análise quantitativa

\begin{tabular}{c|c|c|c|c}
\hline Sexo & Antes & Após & Antes & Após \\
\hline F & 8.5 & 9.5 & 8.0 & 8.0 \\
F & 6.5 & 9.0 & 7.0 & 8.0 \\
M & 8.5 & 8.5 & 7.0 & 6.5 \\
M & 7.5 & 4.0 & 5.0 & 3.0 \\
F & 6.5 & 7.5 & 6.0 & 6.0 \\
F & 7.5 & 10.0 & 6.0 & 8.0 \\
F & 8.0 & 9.0 & 7.0 & 7.0 \\
F & 8.0 & 8.0 & 7.0 & 6.0 \\
F & 7.0 & 9.0 & 6.0 & 7.0 \\
F & 7.0 & 9.5 & 5.0 & 8.0 \\
F & 9.0 & 10.0 & 8.0 & 8.0 \\
F & 7.0 & 9.5 & 6.0 & 8.0 \\
F & 8.0 & 10.0 & 7.0 & 8.0 \\
F & 8.0 & 9.0 & 7.0 & 6.5 \\
M & 8.5 & 10.0 & 7.0 & 8.0 \\
\hline TOTAL & 15.5 & 132.5 & 99.0 & 106.0 \\
\hline
\end{tabular}


Tabela 3. Porcentagem de respostas dadas pelos pais ao questionário.

\begin{tabular}{|c|c|}
\hline $\begin{array}{l}\text { Questão 1. Dificuldade em ler } \\
\text { 1. Apresenta muita dificuldade } \\
\text { 2. Apresenta pouca dificuldade } \\
\text { 3. Lê com facilidade }\end{array}$ & $\begin{array}{r}5 \% \\
57 \% \\
38 \%\end{array}$ \\
\hline $\begin{array}{l}\text { Questão 2. Freqüência com que lê } \\
\text { 1. Com freqüência } \\
\text { 2. Às vezes } \\
\text { 3. Raramente }\end{array}$ & $\begin{array}{r}43 \% \\
52 \% \\
5 \%\end{array}$ \\
\hline $\begin{array}{l}\text { Questão 3. O que mais gosta de ler } \\
\text { 1. Livro de história } \\
\text { 2. Revista em quadrinho } \\
\text { 3. Outros }\end{array}$ & $\begin{array}{r}67 \% \\
25 \% \\
8 \%\end{array}$ \\
\hline $\begin{array}{l}\text { Questão } 4 . \text { O que acontece quando lê } \\
\text { 1. Lê e conta o que leu } \\
\text { 2. Gagueja ao ler }\end{array}$ & $\begin{array}{l}70 \% \\
30 \%\end{array}$ \\
\hline $\begin{array}{l}\text { Questão } 5 . \text { Interesse em leitura depois que aprendeu a ler } \\
\text { 1. Mais interesse } \\
\text { 2. Menos interesse } \\
\text { 3. Ficou indiferente }\end{array}$ & $\begin{array}{r}85 \% \\
5 \% \\
10 \%\end{array}$ \\
\hline $\begin{array}{l}\text { Questão 6. Como os pais acham que podem ajudar os filhos a ler } \\
\text { 1. Incentivando-os a ler em casa } \\
\text { 2. Esclarecendo duvidas } \\
\text { 3. Comprando livros e revistas e quadrinhos } \\
\text { 4. Ensinando a freqüentar bibliotecas } \\
\text { 5. Mostrando a importância da leitura } \\
\text { 6. Pedindo para lerem para eles (pais) } \\
\text { 7. Trazendo livros para casa } \\
\text { 8. Participando com ele na leitura } \\
\text { 9. Observando se procura ler por si } \\
\text { 10. "Ler é um hábito familiar"(dando exemplo) } \\
\text { 11. Querendo que o filho adquira o hábito de ler } \\
\text { 12. Mostrando o valor da leitura }\end{array}$ & $\begin{array}{r}15 \% \\
5 \% \\
15 \% \\
5 \% \\
5 \% \\
5 \% \\
5 \% \\
10 \% \\
15 \% \\
5 \% \\
5 \% \\
10 \%\end{array}$ \\
\hline
\end{tabular}

Tabela 4. Comparação entre os pontos obtidos pelos sujeitos dos dois grupos, em duas situações

\begin{tabular}{l|l}
\hline Grupo experimental x Grupo de controle & Probabilidades \\
\hline Análise qualitativa - situação "antes" & $0,0034^{*}$ \\
Análise qualitativa - situação "depois" & 0,1670 \\
Análise quantitativa - situação "antes" & $0,0213^{*}$ \\
Análise quantitativa - situação "depois & 0,2310 \\
\hline
\end{tabular}

dos com o Grupo Experimental e com o Grupo de Controle, tanto na análise qualitativa, quanto na quantitativa, foi aplicada a prova U de Mann-Whitney (Siegel, 1975: 131-144) aos pontos obtidos pelos sujeitos nas duas fases: "antes e depois" do treinamento.
O nível de significância foi estabelecido em 0,10 , em uma prova bilateral, estando os resultados demonstrados na Tabela 4.

De acordo com os valores demonstrados na Tabela 4 , foram encontradas diferenças significantes 
entre os resultados obtidos pelos dois grupos apenas na situação anterior ao procedimento, sendo que o Grupo Experimental obteve pontos mais elevados do que o Grupo de Controle, nos dois tipos de análise efetuadas.

Com o objetivo de verificar a existência ou não de diferenças significantes entre os resultados dos dois grupos, nas duas fases do estudo, foi aplicada a prova de Wilcoxon (Siegel, 1975: 84-93) aos valores obtidos pelos sujeitos, nas duas análises efetuadas.

O nível de significância foi estabelecido em 0,10 , em uma prova bilateral.

Os resultados estão demonstrados na Tabela 5.
- Prestam atenção ao tipo de leitura preferida pelo filho: $67 \%$ livro de história e $25 \%$ revista em quadrinhos.

- Admitem que o interesse pela leitura está-se acentuando com a aprendizagem: $85 \%$ demonstra maior interesse.

A análise dos resultados do questionário demonstra dois fatos muito importantes: primeiro, é o fato de os pais estarem participando com mais interesse da vida escolar dos filhos, principalmente, porque são pais de baixa renda, os quais não costumam ter a leitura como prática cotidiana. Segundo, porque eles começam a compreender o valor da leitura, como fator essencial ao crescimento intelectual das crianças.

Tabela 5. Comparação entre os pontos obtidos pelos dois grupos de sujeitos, nas duas fases do treinamento.

\begin{tabular}{l|l}
\hline Comparação entre as fases do treinamento & Probabilidades \\
\hline Análise qualitativa - grupo experimental & $0,0157^{*}$ \\
Análise quantitativa - grupo experimental & 0,1549 \\
Análise qualitativa - grupo de controle & $0,0019^{\star}$ \\
Análise quantitativa - grupo de controle & $0,0135^{\star}$ \\
\hline
\end{tabular}

De acordo com os valores demonstrados na Tabela 5, foram encontradas diferenças significantes entre os resultados obtidos pelos sujeitos nas duas fases do estudo, no aspecto qualitativo, tanto para o Grupo Experimental, quanto para o Grupo de Controle, sendo que nos dois casos os valores obtidos na situação posterior ao treinamento foram os mais elevados.

Com relação ao aspecto quantitativo, foram encontradas diferenças significantes apenas entre os resultados obtidos pelos sujeitos do Grupo de Controle, sendo que os valores obtidos na situação posterior ao treinamento foram os mais elevados.

Quanto à percepção dos pais, foi possível verificar, de acordo com a Tabela 3, que:

- Eles preocupam-se com o desempenho de leitura do filho; observe a porcentagem maior nos itens 01,03, 08,09 e 12, da questão de número 6 .

. Percebem que os filhos ainda apresentam dificuldades de leitura, observe o resultado da questão 01 : $57 \%$ ainda apresenta dificuldades.

. Estão conscientes que os filhos ainda não lêem com freqüência: $52 \%$ lêem às vezes.

\section{DISCUSSÃ0}

Obter a colaboração dos pais não é tarefa fácil para a escola, como aponta Topping (1989), ao apresentar o seu procedimento de leitura conjunta. No presente estudo, embora tenha havido todo o empenho do pessoal da escola e o auxílio dos pesquisadores, a colaboração que se pôde obter parece ter sido fruto muito mais da participação dos alunos, do que dos referidos esforços. O interesse dos alunos, observado de forma assistemática, durante os encontros na escola, e relatado também pela professora, parece ter movido os pais para colaborarem de forma mais efetiva. Isso vem reforçar os dados obtidos por Grolnick e Slowiaczeck (1994), segundo os quais o desempenho do filho na escola pode influenciar o envolvimento da mãe. Portanto, esses dados sugerem que o procedimento de leitura, utilizado neste estudo, obteve indiretamente, ou seja, através dos filhos, a participação dos pais.

A partir do momento em que os pais começaram a se envolver, então o procedimento utilizado de leitura conjunta pode ter possibilitado as condições para uma boa mediação dos mesmos, ou de outro ouvinte (avó, 
tia), de acordo com os critérios propostos por Feuerstein (1980) e Klein (1992), quais sejam: focalização, quando propicia que o aluno preste atenção ao texto escolhido; expansão, quando o conduz a dar respostas inferenciais e avaliativas; afetividade, quando o ouvinte transmite significados e emoções ligadas ao texto; recompensa, quando são mediados sentimentos de competência, através do elogio, promovendo a auto-estima positiva, e regulação, quando utiliza os procedimentos corretivos.

Assim, parece que o procedimento de leitura conjunta pode fornecer a pais e mães pistas para auxiliálos a serem bons mediadores de aprendizagens escolares, contribuindo em particular para aumentar o potencial de aprendizagem da leitura, formando leitores proficientes.

Um outro dado que merece ser discutido, refere-se à maior participação da mãe no presente estudo. Esta, não só compareceu, em maior número, às reuniões da escola, mas também ouviu o filho ler mais vezes, que o pai, e foi a mãe que respondeu o questionário proposto. Isso retrata o que comumente ocorre, nacional e internacionalmente (Bhering et al., 1999), indicando que a cultura escolar ainda não incluiu o pai como colaborador. Talvez a mãe tenha mostrado maior disponibilidade afetiva e pessoal, como ressaltam Steinberg, Dornbush e Darling (1992), mesmo não dispondo de muito tempo livre, como é necessário ao pai para se envolver com a vida escolar do filho, conforme pesquisa já referida de Freitas, Maimoni e Siqueira (1994).

Ainda um outro questionamento a ser feito, com base nos estudos de Marturano (1997), refere-se ao apoio dado ao aluno pela família e pela escola às suas atividades de leitura, o que pode tê-lo fortalecido em relação a isso, aumentado suas condições de resiliência e favorecendo a aprendizagem escolar do mesmo, já que o desempenho verbal é muito valorizado pela escola.

Além disso, as informações transmitidas, através dos textos que os alunos liam para membros da família, talvez tenham contribuído para melhorar o nível de leiturização destes, da mesma forma como Santos e Joly (1996) observaram em seus estudos. Contudo, o único dado sugestivo nesse sentido, que obtivemos, foi o referente ao interesse dos pais por leitura, através de suas respostas ao questionário, pois não era objetivo deste estudo verificar os efeitos do procedimento de leitura conjunta no desempenho dos pais. Se realmente esse efeito ocorreu, a família passou a contar com mais recursos educacionais, para promover o desenvolvimento cognitivo da criança, recursos que, como mostra Marturano (1997), associados a maior acesso a passeios e brinquedos, podem conduzir a um melhor desempenho em leitura e escrita.

Embora a pesquisa tenha produzido um resultado quantitativo, foram os resultados qualitativos que mais se destacam para uma discussão.

A maior concentração de respostas erradas ocorreu com as questões de caráter inferencial, o que demonstra que esse tipo de leitura, crucial durante o processo de aprendizagem, não tem sido devidamente trabalhado nas escolas. As de caráter avaliativo também tiveram alta incidência de erros, o que permite inferir que nas escolas é pouco solicitado ao aluno-leitor que se posicione criticamente diante do que lê, não atendendo ao que recomenda Dell'Isolla (1991). Assim, observa-se que apenas o Grupo de Controle melhorou no aspecto quantitativo, no segundo texto para avaliar a proficiência em compreensão de leitura, evidenciando que a escola desenvolve um trabalho mais nesse sentido, do que investindo nos aspectos qualitativos, tal como foram definidos no presente estudo.

De qualquer forma, o segundo texto aplicado ao grupo, embora com um número menor de erros, apresentou também maior incidência nos dois níveis de leitura aludidos acima.

\section{Conclusĩo}

A partir dos dados apresentados, pode-se verificar que os ganhos obtidos pelos alunos, em proficiência em leitura, foram aqueles relacionados aos aspectos qualitativos, conforme os critérios adotados na presente pesquisa. Assim, o critério quantitativo de número de acertos indicou a ação da escola nesse sentido, já que o Grupo de Controle mostrou ganhos nesse aspecto, enquanto o procedimento de leitura conjunta parece ter privilegiado o aspecto qualitativo. Como o grupo de controle também apresentou ganhos nesse aspecto, não se pode afirmar que apenas o procedimento utilizado tenha sido responsável pelo desempenho melhor dos alunos em compreensão de leitura.

Entretanto, é possível observar que o grupo, que passou por esse procedimento, obteve um maior nú- 
mero de pontos, indicando a possibilidade de, pela ação mediadora dos pais, haver um aumento no potencial de aprendizagem dos alunos desse grupo em leitura, além do que a escola pode conseguir.

Talvez um tempo maior de exposição ao procedimento proposto, com maior quantidade de sessões de leitura em casa possa conduzir a diferenças mais acentuadas, como ocorreu nos estudos de Topping (1994), cujos alunos beneficiários do estudo, faziam leituras diárias para seus pais.

\section{REFERÊNCIAS}

Bettelheim, B. \& Zelan, K. (1992). Psicanálise da Alfabetização: um estudo psicanalítico do ato de ler. Porto Alegre: Artes Médicas.

Bhering. E. \& Siraj-Blatchford, I. (1999). A relação escolapais: um modelo de trocas e colaboração. Cadernos de Pesquisa, 106,191-216.

Braggio, S.L.B.(1992). Leitura e alfabetização: da concepção mecanicista à sociopsicolingüística. Porto Alegre: Artes Médicas.

Bortone, M. E. (1999). Linguagens e Educação. Uberaba: UNIUBE/Cone Sul.

Bortone, M. E. (1996). O significado do letramento na aprendizagem da língua materna. Solta a Voz, 8, 55-67.

Bortone, M. E., MAIMONI E. H. \& PAIVA, T. O. (2000). Estudo preliminar sobre o envolvimento de pais no processo de construção da leitura da criança na escola. Anais do V CONPE, Itajaí (SC), 270.

Bradley, R. H.; Caldwell, B.M. \& Rock, S. L. (1988). Home environment and school performance: a ten-year followup and examination of three models of environmental action. Child Development, 59, 852-867.

Citelli, A. O. (1990). Conceitos de leitura. São Paulo: Ática.

Dell'isola, R. L. P. (1991). Leitura: Inferências e contexto sociocultural. Belo Horizonte: Universitária.
Há que se considerar ainda que a escola, onde o presente estudo foi realizado, tem como um de seus objetivos pedagógicos, desenvolver o hábito de leitura nos alunos. Para tanto, a bibliotecária que participou do trabalho de distribuição dos textos, orientava também a leitura dos demais alunos do grupo de controle, o que pode ter influenciado nos resultados ora apresentados.

Delors, J. (1999). Educação: um tesouro a descobrir. São Paulo: Cortez.

Dinucci, E. P. (1997). Interesses e dificuldades dos pais na alfabetização dos filhos. Psicolologia Escolar e Educacional, 1 (2, 3), 23-28.

Feuerstein, R. (1980). An Instrumental Enrichment: an intervention program for cognitive modificability. Baltimore: University Park Press.

Freitas, G. B., Maimoni, E. H. \& Siqueira, M. M. M. (1994). Escala reduzida de envolvimento de pais na vida escolar do aluno (EEPVA). XXIV Reunião Anual de Psicologia, da Sociedade Brasileira de Psicologia, 437.

Grolnick, W. S. \& Slowiaczeck, M. L. (1994). Parent's involvement in children's schooling: a multidimensional conceptualization and motivational model. Child Development, 65, 237-252.

Kleiman, A. (1997). Texto e Leitor: aspectos cognitivos da leitura. São Paulo, Pontes.

Kleiman, A. (1989). Leitura: ensino e pesquisa. Campinas: Pontes.

Klein, P. (1992). More intelligent and sensitive child (MISC): a new look at an old question. International Journal of Cognitive Education and Mediated Learning, 2 (2), 105-115.

Linhares, M. B. M.(1995). Avaliação assistida: fundamen- 
tos, definição, características e implicações para a avaliação psicológica. Teoria e Pesquisa, 11 (1), 23-31.

Maimoni, E. H. (1998). Envolvimento de pais na vida escolar do aluno - problemas de definição e medida. Revista da SPTM, 1 (1), 15-18.

Maimoni, E. H \& Miranda, A. A. B.(1999). Uma proposta de avaliação do envolvimento dos pais na vida escolar do filho. Anais do IV Congresso e IV Mostra de Ciências Humanas e Artes (CD-room), Viçosa (MG).

Marturano. E. M. (1997). A criança, o insucesso escolar precoce e a família: condições de resiliência e vulnerabilidade. Estudos em Saúde Mental. Ribeirão Preto: Comissão de pós-graduação em Saúde Mental da FMRP/USP, 132-149.

McBride, S. L. (1999). Family-centered practices. Young Children, 62-68.

Santos, A. A. A. \& Joly, M. R. C. (1996). Lendo histórias em família: influência sobre o vocabulário infantil e desempenho em leitura e escrita. Psicologia Escolar e Educacional, 1 (1), 39-44.
Steinberg, L.; Lamborn, S. D.; Dornbush, S. M. \& Darling, N. (1992). Impact of parenting practices on adolescent achievement: authoritative parenting, school involvement, and encouragement to succeed. Child Development, 63, 1266-1281.

Topping, K. (1989). Lectura conjunta : una poderosa técnica al servicio delos padres. Comunicación, Lenguaje y Educación, 3-4, 143-151.

Topping, K. (1994). Paired reading, spelling and writting: the handbook for parent and peer tutoring in literacy. Londres: Cassell.

Topping, K. \& Whiteley, M.( 1990). Participant evaluation of parent-tutored and peer tutored projects in reading. Educational Research, 32 (1), 14-32.

Vygotsky, L. S. (1988). A formação Social da Mente: o desenvolvimento dos processos psicológicos superiores. São Paulo: Martins Fontes.

Recebido em: 19/06/2001

Revisado em: 22/07/2001

Aprovado em: 06/11/2001 


\section{ANEXO 1}

Procedimento de Leitura Conjunta

(adaptado de Keith Topping, 1989)

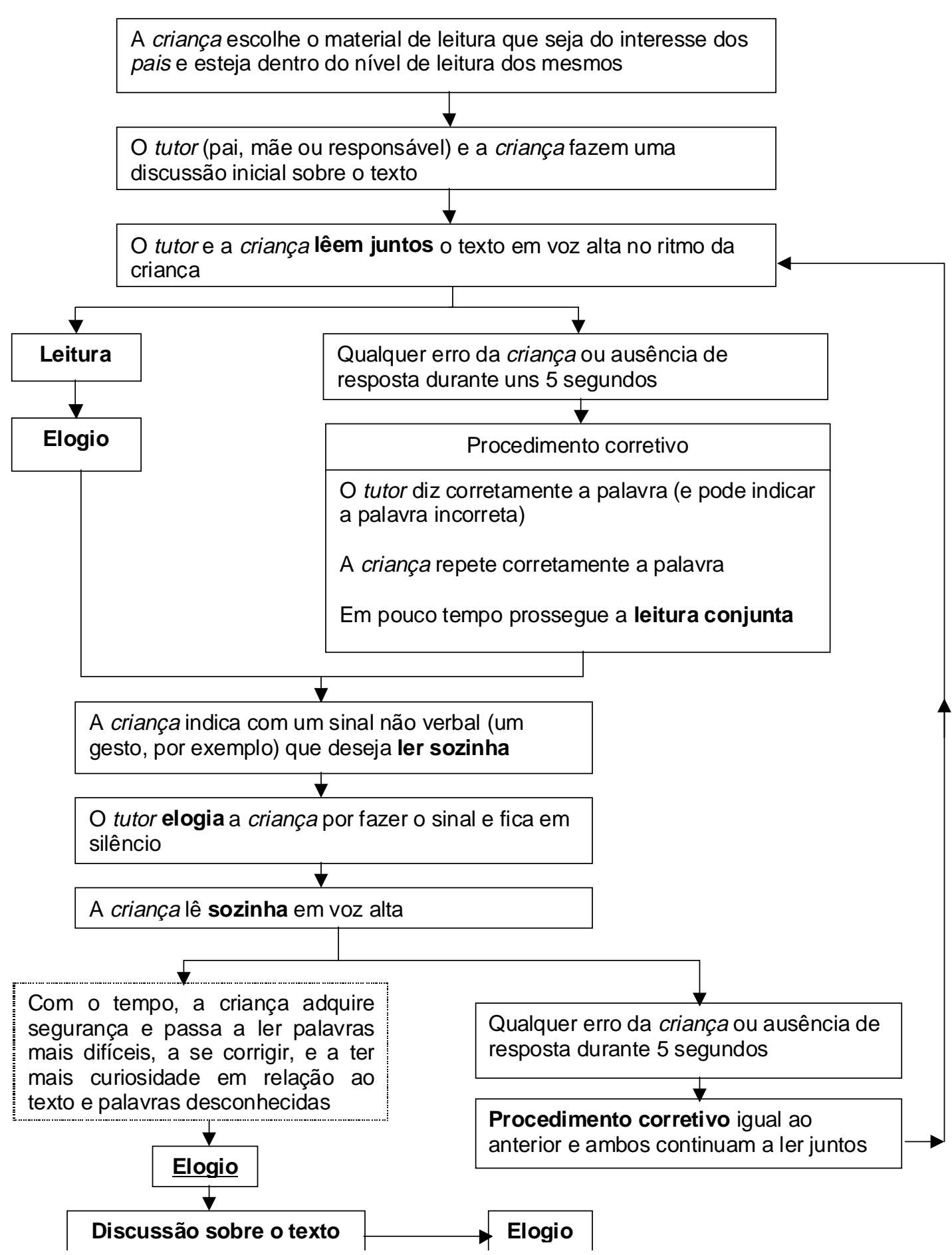

